\title{
вMJ Global Health Panacea or pitfall? The introduction of community health extension workers in Uganda
}

\author{
David Musoke (D) , ${ }^{1}$ Rawlance Ndejjo, ${ }^{1}$ Edwinah Atusingwize, ${ }^{1}$ \\ Charles Ssemugabo, ${ }^{1}$ Amanda Ottosson, ${ }^{2}$ Linda Gibson, ${ }^{3}$ Peter Waiswa ${ }^{4}$
}

\begin{abstract}
To cite: Musoke D, Ndejjo R, Atusingwize $\mathrm{E}$, et al. Panacea or pitfall? The introduction of community health extension workers in Uganda. BMJ Global Health 2020;5:e002445. doi:10.1136/ bmjgh-2020-002445
\end{abstract}

Handling editor Seye Abimbola

Received 29 February 2020

Revised 2 June 2020

Accepted 5 June 2020
Check for updates

(c) Author(s) (or their employer(s)) 2020. Re-use permitted under CC BY-NC. No commercial re-use. See rights and permissions. Published by BMJ.

'Department of Disease Control and Environmental Health,

School of Public Health, College of Health Sciences, Makerere University, Kampala, Uganda ${ }^{2}$ Independent Consultant, Kampala, Uganda

${ }^{3}$ School of Social Sciences, Nottingham Trent University, Nottingham, UK

${ }^{4}$ Department of Health Policy, Planning and Management, School of Public Health, College of Health Sciences, Makerere University, Kampala, Uganda

Correspondence to

Dr David Musoke;

dmusoke@musph.ac.ug

\section{BACKGROUND}

In 2018, the world commemorated 40 years of the Alma Ata Declaration on primary health care (PHC) which emphasised the importance of Community Health Workers (CHWs) in ensuring its vision of health for all. In line with the declaration, Uganda launched a CHW programme in 2001 in an effort to address the high disease burden and critical shortage of health professionals, as well as improve equitable access to health services. ${ }^{1}$

The programme established a cadre of volunteers charged with the responsibility of empowering communities to take control of their own health and well-being, and actively participate in the management of local health services. These volunteers in Uganda are called Village Health Teams (VHTs) and recognised as 'health centre I', being the first contact of the community with the health system. ${ }^{23}$ The main roles of the VHTs include: carrying out health education at household and community levels; conducting house-to-house visits for health improvement; participating in integrated community case management (iCCM) of childhood illnesses of pneumonia, malaria and diarrhoea; referral of patients to health facilities; as well as mobilisation of communities for public health interventions such as immunisation of children and distribution of mosquito nets.

VHTs are lay persons with the ability to read and write preferably in their local language, identified by their community, and offered basic training between 5 to 10 days on several topics such as communication, community mobilisation, child growth and development, sexual and reproductive health, sanitation and hygiene and common diseases such as malaria. These VHTs, who are supposed to be four per village, are not formally paid but sometimes provided with infrequent and nonstandardised support including non-financial
Summary box

The Uganda Ministry of Health is planning to introduce new Community Health Extension Workers (CHEWs) who would be institutionalised, paid a monthly allowance, and work closely with existing Village Health Teams (VHTs) who are community volunteers.

- The introduction of CHEWs is likely to have several benefits to the country's health system, including availability of another health cadre offering majorly preventive and selected curative services, and supporting the work of VHTs including supervision.

- But there are foreseeable concerns that could affect the CHEW programme. Just like VHTs, CHEWs would require support systems: performance management, regular refresher trainings, supervision from health practitioners, and availability of necessities and supplies.

- Given that two CHEWs would be employed per parish (the sub-counties of Uganda are divided into parishes, which are further divided into villages) in comparison with four VHTs per village, VHTs would remain crucial in supporting the community health system.

- However, there is a likelihood that with the introduction of CHEWs, VHTs would be further neglected hence affecting community health outcomes. Hence, there is need for a holistic approach to introduce and adequately support the CHEWs.

- Even with the introduction of CHEWs, deliberate effort to strengthen the existing VHT programme is necessary to improve community health.

incentives such as t-shirts and bicycles, many times by health development partners working closely with the Ministry of Health $(\mathrm{MOH})$. They are often provided with a refund of transport costs to attend meetings, and whenever called on for any official activity which is sometimes insufficient for the purpose. ${ }^{4}$ The work of VHTs is supported and supervised by a VHT parish coordinator and/or a health practitioner working in the area, with 
the overall supervision of the District Health Educator. Note that the sub-counties of Uganda are divided into parishes, which are further divided into villages.

Since 2001, the VHT programme has registered improved health outcomes especially contributing to reducing morbidity and mortality among children under 5 years of age particularly for malaria, pneumonia and diarrhoea under iCCM of childhood illnesses. ${ }^{4-7}$ However, challenges regarding training, transportation, remuneration, motivation and retention of VHTs continue to affect the programme. ${ }^{8-11}$ With an interest to strengthen the community health system and further improve health outcomes with emphasis on disease prevention, the $\mathrm{MOH}$ commissioned a comprehensive national assessment of the VHT programme in 2015 to establish its status and functionality in order to improve planning and health service delivery to communities. ${ }^{4}$ The assessment identified critical gaps in the VHT programme regarding funding, training, supervision and coordination of the programme across all levels of the health system. After the assessment, a desk-based review and benchmarking activity was conducted to gain a deeper understanding of other countries' experiences.

Using evidence gained, the $\mathrm{MOH}$ recommended the introduction of the Community Health Extension Workers (CHEWs) policy and strategy in Uganda, largely modelled after the Ethiopian Health Extension Workers programme. The CHEWs would be formally institutionalised in the local government healthcare delivery structure, with two of them situated at parish level. The CHEWs are expected to be involved in various promotive, preventive and basic curative services at community and health facility levels. They will directly supervise and oversee the work of VHTs in communities. As opposed to the VHTs, CHEWs would need to be nominated by their parish, between the age of 20 to 35 years, have a minimum of ordinary level education, be fluent in both English and the local language, undergo a 6 months training before deployment and paid a standard monthly consolidated allowance by Government. ${ }^{12}{ }^{13}$ Approximately, 15000 CHEWs are planned to be rolled out to an estimated 7500 parishes across the country over a 5 -year period by the $\mathrm{MOH}$ with the support of implementing partners. ${ }^{13}$

A recent publication in BMJ Global Health highlighted the potential challenges of implementing the CHEW programme in Uganda including logistical and financial concerns as well as the relationship between CHEWs and VHTs. ${ }^{14}$ In this article, we explore the pros and cons of this CHEWs strategy as well as propose what needs to be done for its success based on our experiences of working in community health in Uganda.

\section{PROS}

Countries such as Ethiopia, Nigeria and Kenya have developed and implemented paid CHW programmes to improve access to PHC services especially in low-resource communities and among vulnerable populations. These
CHW programmes are aimed at providing quality promotive, preventive and selected curative health services at PHC centres in an accessible and equitable manner to all sections of the population, with special attention to mothers and children. ${ }^{15}$ In Ethiopia, two health extension workers are posted per primary health centre which serves a catchment population of 5000 people or more, ${ }^{16} 17$ while in Nigeria 20 CHEWs serve a population of 10000 people. $^{18}$ Paid CHWs undergo a relatively longer formal pre-service training (such as 36 months in Nigeria ${ }^{18}$ ) in comparison with volunteer CHWs, are usually required to have substantive level of formal education, and are normally residents of the community they serve ${ }^{19}$ as is normally the case with volunteer CHWs.

Unlike volunteer CHWs, CHEWs receive a financial incentive of a monthly salary. ${ }^{15}$ Where CHWs such as CHEWs have been financially compensated, they have made substantial impact on health outcomes of populations especially on maternal health. ${ }^{20-22}$ Indeed, the WHO has recommended remuneration of CHWs with a financial package commensurate with their work and training. ${ }^{23}$ CHWs effectiveness has been attributed to performance management, data driven decision making, cordial working relationships with communities, mentorship and supervision provided by health managers and provision of several innovative avenues for improving performance. ${ }^{24}$ Such experiences from other countries should be considered in implementation of the proposed CHEW programme in Uganda.

However, many stakeholders in Uganda are asking whether the introduction of CHEWs is the much-needed reform to accelerate Universal Health Coverage. Or could there be a missed opportunity of strengthening the existing CHW programme building on earlier successes? In our view, the proposed CHEWs are likely to have some benefits to the country's health system. Introducing another health cadre focussed majorly on health promotion and disease preventive among the population would increase access to $\mathrm{PHC}$ which would lead to better health outcomes. ${ }^{24}$ Indeed, services of the CHEWs would be a complimentary link to other health professionals in the country including nurses, health assistants and clinical officers who all support community health. ${ }^{12}$

In addition, the CHEWs could significantly support the work of VHTs including their direct supervision, data collection and reporting. Referral and follow-up of patients from communities to health facilities is also likely to improve if the CHEWs work closely with VHTs in their day-to-day activities within their respective parishes. Since the CHEWs would spend part of their time at primary health centres, they would not only contribute to supporting community health but also service delivery at health facilities by reducing existing health worker burden through assisting in diagnosis and management of simple illnesses as seen elsewhere. ${ }^{1821}$ 


\section{CONS}

However, there are a number of foreseeable concerns that if not adequately addressed, could negatively affect the CHEW programme and the community health system in general in Uganda. For optimum performance of CHEWs, they would require adequate support systems including performance management, regular refresher trainings, availability of necessities and supplies such as drugs, sufficient logistics such as motorcycles for transportation, regular supervision, mentorship from health practitioners, as well as community trust and acceptance. Logistical support including transportation is not only crucial for the performance of CHEWs but also in the proposed supervision of VHTs by the CHEWs in the community. These concerns have for long been known to affect the wider health workforce in Uganda including among VHTs. ${ }^{48}$ Therefore, introduction of CHEWs without addressing these health system challenges would most likely result in a health cadre that is not adequately supported to yield the desired results in improving population health.

Whereas the proposed two CHEWs per parish would be instrumental in supporting VHTs in that area, they would probably have minimal impact in reaching the vast population in several communities given that some parishes in the country have over 60000 people. ${ }^{25}$ Furthermore, in a parish with over 25 villages, two CHEWs could be working in a geographical location with over 100 VHTs as one village is meant to be supported by four VHTs. This situation emphasises that even with deployment of CHEWs, the role of VHTs remains crucial in supporting the community health system. However, there is a likelihood that with the introduction of CHEWs, VHTs would be further neglected if not phased out hence undermining their role in providing PHC and public health services in the community. Indeed, the several challenges among VHTs identified by the national VHT assessment including training, coordination, supervision, monitoring, motivation and reporting, ${ }^{4}$ that are said to have contributed to introduction of the CHEWs,${ }^{13}$ would not be completely addressed by this new cadre. It would therefore be important that concerted efforts are made to address the VHT-specific challenges established in the national survey to compliment and strengthen the proposed CHEW programme. More so given the evidence that the roles of VHTs are crucial for the performance of CHEWs and achieving desirable health outcomes in the community.

Given that CHEWs would be paid a monthly consolidated allowance while incentives for the existent VHTs have remained low and non-financial, there is a high possibility that the relationship between the two cadres may not be cordial which would potentially affect health service delivery in the community. ${ }^{14}$ Moreover, there is no guarantee that with the provided remuneration, the CHEWs would deliver on what is expected of them especially with a high record of absenteeism and low supervision rates reported among health workers in Uganda. ${ }^{26}$
Therefore, performance management at community level must be prioritised and strengthened.

Furthermore, the $\mathrm{MOH}$ should prioritise the urgent need to address the VHT concerns so as to benefit the community health system beyond the single cadre of CHEWs. In addition, the challenges affecting the wider health workforce in the country need to be addressed before the introduction of the CHEWs strategy. A mindset shift is further needed by the government, health workers, communities and other stakeholders to move from prioritisation of curative services to health promotion and disease prevention. Although it has been recommended that the existing VHTs would be prioritised during the selection of CHEWs, very few will be eligible given majority are above the entry age limit of 35 years. ${ }^{4}$ Minimal integration of VHTs into CHEWs is therefore likely to further negatively affect community embeddedness as well as the relationship between the two cadres.

Another concern is that the role being assigned to the CHEWs is one that health assistants, a cadre of certificate level Environmental Health professionals supposed to supervise VHTs, are meant to contribute to. ${ }^{2}$ It is therefore more plausible and efficient to enhance the performance of such a workforce, who receive a 2-year training to effectively carry out their responsibilities, than introduce another 6-month trained cadre to play closely related roles. With the introduction of this new strategy, CHEWs would serve as the current health centre 2s to coordinate their activities and offer services within the community. ${ }^{13}$ Despite the proposal that CHEWs would spend $60 \%$ of their time in the community, being based at health centres could likely lead to further extension of essential services away from the community. This may further disenfranchise community members and contribute to poor health outcomes given the long distances to health facilities in many areas. ${ }^{27}$ Another challenge that VHTs have been found to face is the lack of a clear career path. ${ }^{4}$ Although introduction of CHEWs may provide an opportunity for some VHTs particularly those with ordinary level qualification and within the age limit, the career path for CHEWs is yet to be clarified which could affect the strategy and its impact.

\section{CONCLUSION}

From the pros and cons of the proposed CHEWs strategy, it is evident that the benefits of the programme could be achieved through strengthening the existing CHW structure and enhancing the performance of related cadres. As the CHEWs policy could be introduced by the Government of Uganda, a community health systems approach should be adopted to support its implementation if desired results are to be achieved. First of all, there should be short-term and long-term guiding principles during roll-out of CHEWs throughout the country. These principles should: consider poor performing and hard to reach areas including having specific strategies 
for such communities; complement and not compete with existing health systems structures especially VHTs; and ensure emphasis is predominantly preventive and community based.

In addition, there is need to strengthen curative care at health facilities where cases from the community are referred to in terms of availability of infrastructure, human resources, as well as medicines and other supplies. Implementation of the CHEWs programme should also be data driven to inform scale-up such as embedding operational research, and having a strong performance, monitoring and evaluation system including impact and economic evaluations. Given the high investment of Government and health development partners in the CHEWs strategy, there is need for accountability for results to ensure value for money to all stakeholders. For example, innovative financing mechanisms such as performance-based financing as well as performance-based incentives for CHWs could be considered to enhance the community health system. A strong legal and policy framework is also needed to support the programme which should include a clear coordination structure and modalities of how health development partners would work with CHEWs and VHTs at both national and lower levels.

Lastly, CHEWs should not be looked at in isolation but rather in context of the broader community health system, which needs to be formally defined and mapped out. Indeed, financing, leadership and governance, service delivery, information systems as well as consideration of the strengths and weaknesses of communities in which they would work are critical to the success of the CHEWs, and more importantly improving health outcomes. Overall, achievement of significant community health outcomes would require a deliberate effort to strengthen the existing VHT programme especially through regular training, improved incentives for motivation, and enhanced supervision.

Twitter David Musoke @DavidMusoke14

Acknowledgements We acknowledge all community health stakeholders we have worked with throughout Uganda including the Ministry of Health, district health teams, health practitioners, non-governmental organisations, village health teams, local leaders and the community.

Contributors DM, RN and PW conceptualised the manuscript and were involved in its writing. EA, CS, A0 and LG were involved in literature review and writing the manuscript. All authors read and approved the final manuscript.

Funding The authors have not declared a specific grant for this research from any funding agency in the public, commercial or not-for-profit sectors.

Competing interests None declared.

Patient consent for publication Not required.

Provenance and peer review Not commissioned; externally peer reviewed.

Data availability statement All data relevant to the study are included in the article.

Open access This is an open access article distributed in accordance with the Creative Commons Attribution Non Commercial (CC BY-NC 4.0) license, which permits others to distribute, remix, adapt, build upon this work noncommercially, and license their derivative works on different terms, provided the original work is properly cited, appropriate credit is given, any changes made indicated, and the use is non-commercial. See: http://creativecommons.org/ licenses/by-nc/4.0/.
ORCID iD

David Musoke http://orcid.org/0000-0003-3262-3918

\section{REFERENCES}

1 Ministry of Health. National health policy. Kampala, Uganda, 1999.

2 Ministry of Health. Health sector strategic plan II. Kampala, Uganda, 2005.

3 Ministry of Health. Health sector strategic plan. Kampala, Uganda, 2000.

4 Ministry of Health. National village health teams assessment in Uganda. Kampala, Uganda, 2015.

5 Brenner JL, Kabakyenga J, Kyomuhangi T, et al. Can volunteer community health workers decrease child morbidity and mortality in southwestern Uganda? an impact evaluation. PLoS One 2011;6:e27997.

6 Kayemba Nalwadda C, Guwatudde D, Waiswa P, et al. Community health workers - a resource for identification and referral of sick newborns in rural Uganda. Trop Med Int Health 2013;18:898-906.

7 Wanduru P, Tetui M, Tuhebwe D, et al. The performance of community health workers in the management of multiple childhood infectious diseases in Lira, northern Uganda - a mixed methods cross-sectional study. Glob Health Action 2016;9:33194.

8 Kimbugwe G, Mshilla M, Oluka D, et al. Challenges faced by village health teams (VHTs) in Amuru, Gulu and Pader districts in northern Uganda. Open J Prev Med 2014;4:740-50.

9 Turinawe EB, Rwemisisi JT, Musinguzi LK, et al. Selection and performance of village health teams (VHTs) in Uganda: lessons from the natural helper model of health promotion. Hum Resour Health 2015:13:73.

10 Brunie A, Wamala-Mucheri P, Otterness C, et al. Keeping community health workers in Uganda motivated: key challenges, facilitators, and preferred program inputs. Glob Health Sci Pract 2014;2:103-16.

11 Mays DC, O'Neil EJ, Mworozi EA, et al. Supporting and retaining village health teams: an assessment of a community health worker program in two Ugandan districts. Int J Equity Health 2017;16:129.

12 Ministry of Health. Health sector development plan 2015/16 2019/20. Kampala, Uganda, 2015.

13 Ministry of Health. VHT / community health extension workers, 2018 Available: http://health.go.ug/community-health-departments/vhtcommunity-health-extension-workers [Accessed 9 Oct 2018].

14 O'Donovan J, Stiles CE, Sekimpi D, et al. Potential challenges of implementing the community health extension worker programme in Uganda. BMJ Glob Health 2018;3:e000960.

15 Pathfinder International. The Ethiopian health extension program, 2008.

16 Liu A, Sullivan S, Khan M, et al. Community health workers in global health: scale and scalability. Mt Sinai J Med 2011;78:419-35.

17 UNICEF. Evaluation report of the community health strategy implementation in Kenya, 2010. Available: https://www.unicef. org/evaldatabase/files/14_2010_HE_002_Community_Strategy Evaluation report October 2010.pdf [Accessed 15 Dec 2018].

18 Federal Ministry of Health. Task-shifting and task-sharing policy for essentialhealth care services in Nigeria, 2014. Available: https:// advancefamilyplanning.org/sites/default/files/resources/Nigeria\% 20taskshifting\%20policy-Aug2014\%20REVISEDCLEAN\%20_ Approved\%200ctober\%202014.pdf [Accessed 20 Dec 2018].

$19 \mathrm{HEEC}, \mathrm{FMOH}$. Health extension program in Ethiopia. Addis Ababa: Ethiopia Federal Ministry of Health, 2007.

20 Workie NW, Ramana GN. The health extension program in Ethiopia. Washington D.C., USA: World Bank, 2013.

21 Gebrehiwot TG, San Sebastian M, Edin K, et al. The health extension program and its association with change in utilization of selected maternal health services in Tigray region, Ethiopia: a segmented linear regression analysis. PLOS One 2015;10:e0131195.

22 Sotunsa JO, Vidler M, Akeju DO, et al. Community health workers' knowledge and practice in relation to pre-eclampsia in Ogun state, Nigeria: an essential bridge to maternal survival. Reprod Health 2016;13:108.

23 Fetene N, Linnander E, Fekadu B, et al. The Ethiopian health extension program and variation in health systems performance: what matters? PLoS One 2016;11:e0156438.

24 World Health Organization. WHO guideline on health policy and system support to optimize community health worker programmes. Geneva, Switzerland, 2018.

25 Uganda Bureau of Statistics. The national population and housing census 2014 - main report. Kampala, Uganda, 2016.

26 Tweheyo R, Daker-White G, Reed C, et al. 'Nobody is after you; it is your initiative to start work': a qualitative study of health workforce absenteeism in rural Uganda. BMJ Glob Health 2017;2:e000455. 
27 Musoke D, Boynton P, Butler C, et al. Health seeking behaviour and challenges in utilising health facilities in Wakiso district, Uganda. Afr 